Article

\title{
Application of Blockchain Technology in Sustainable Energy Systems: An Overview
}

\author{
Jiani $W^{1, *}$ and Nguyen Khoi Tran ${ }^{2}$ \\ 1 School of Economics and Management, Chang'an University, Xi'an 710064, China \\ 2 Maritime Institute, Nanyang Technological University, Singapore 639798, Singapore; khoi@ntu.edu.sg \\ * Correspondence: jianiwu@chd.edu.cn; Tel.: +86-029-8233-4506
}

Received: 2 August 2018; Accepted: 26 August 2018; Published: 28 August 2018

\begin{abstract}
The Energy Internet has become a hot topic for the integration of sustainable energies. However, as a result, there are numerous sustainable energy forms and participants, the system is extremely complex, and some key issues are difficult to overcome, such as the control and management of distributed sustainable energy forms. On the other hand, blockchain technology consists of distributed data storage, peer-to-peer transmission, a consensus mechanism, encryption algorithms, and smart contracts. Applying the technical advantages of the blockchain to the Energy Internet can solve many of the problems that hinder its development. The purpose of this paper is to review the development of blockchain and the Energy Internet, and provide some references for the possible applications of blockchain technology to the Energy Internet. Firstly, the definition and characteristics of blockchain and the Energy Internet are introduced in detail. Secondly, the compatibility of the two is analyzed. Then, several application scenarios of blockchain in the Energy Internet are put forward. Finally, the challenges that still exist when applying the current blockchain technology to the Energy Internet are analyzed.
\end{abstract}

Keywords: blockchain; energy internet; sustainable energy

\section{Introduction}

With the rapid development of sustainable energy technologies and network technologies, the Energy Internet represented by "New Energy + Internet" has become the new frontier of technological innovation in the international energy academia and industry. Moreover, it is also an important development direction in the field of energy after the smart grid [1]. However, the Energy Internet involves more forms of energy and more participants, its energy and information are tightly integrated, and some challenges are difficult to overcome, such as control and management of distributed sustainable energy forms. So far, research on the Energy Internet is still at the level of theoretical research and architecture design. The Energy Internet that is actually running is still rare. Therefore, new technologies are urgently needed to help the construction and marketization of the Energy Internet [2-4].

In November 2008, a scientist named Nakamoto Sang published a paper entitled "Bitcoin: A Peer-to-Peer Electronic Cash System". The article proposes that what is needed is an electronic payment system based on cryptographic proof instead of trust, allowing any two willing parties to transact directly with each other without the need for a trusted third party. Besides, he created the first block of the blockchain in January 2009, which is also known as the "Genesis Block". However, people did not pay attention to the concept of blockchain at that time. As the Bitcoin system was operated without security for many years, people started to tap the underlying technology that supports the Bitcoin system: blockchain technology [5]. On 31 October 2015, the Economist published a cover article entitled "The promise of the blockchain: the trust machine" [6], which argued that blockchain technology 
has great potential to change the human-to-human cooperation model and business cooperation model, and it is a technology that creates trust. The publication of this article created widespread attention for the blockchain technology, as depicted in Figure 1, the Baidu index on the topic of blockchain rises rapidly recently especially since 2017. Blockchain is considered as the fifth disruptive innovation of the computing paradigm, after mainframe computers, personal computers, the internet, and mobile/social networks. It is also the fourth milestone in the history of human credit evolution following blood, pro-credit, precious metal credit, and central bank currency credit [7]. At present, the exploration of blockchain technology is leading in the financial industry, while applications in other industries are rapidly expanding. The key technologies in blockchain such as consensus mechanisms, encryption algorithms, smart contracts, and distributed data storage can be used to solve some of the difficult problems in the construction of the Energy Internet.

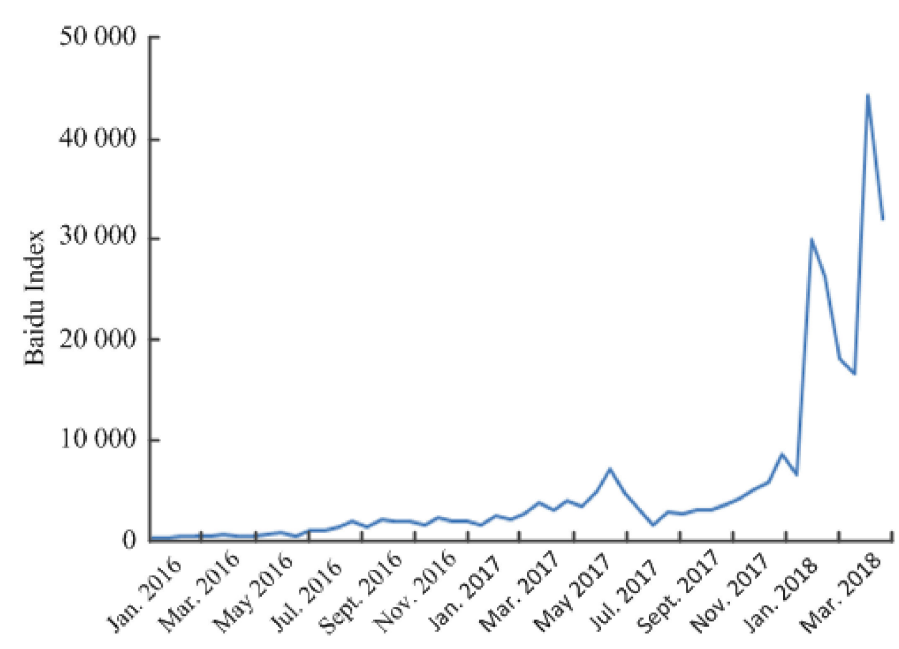

Figure 1. Baidu index on the topic "blockchain".

Microgrids and distributed sustainable energy are contained in Energy Internet. These two elements represent both producer and costumer. Furthermore, their activities of production, consumption, and transaction need to be managed independently. The energy and information between systems are highly interconnected, and the transparency and security of data must be concerned with the basis of intelligent transactions [8]. According to this principle, if the Energy Internet uses a traditional solution to establish a central institution as the trusted center, all of the transactions would be transported through the central institution. In this case, whether the central institution can control or manage effectively would be an unpredictable question [9]. Additionally, the Energy Internet allows access to various forms of energy, that is, the openness of the Energy Internet, which indicates a great challenge to the transparency of the central institution.

The characteristics of the Energy Internet and blockchain technologies are consistent. In this scenario, if the blockchain is applied to the Energy Internet, a decentralized energy trading platform that is based on the consensus mechanism can be set. Meanwhile, automated and efficient trading are guaranteed by the implementation of smart contrasts. Participants are allowed to query transaction data in the blockchain, which ensures the transparency of the whole platform. Additionally, data in the system is protected by encryption algorithms and distributive data storage. Above all, blockchain technology can be applied to the Energy Internet, and it is feasible [10].

Presently, most researchers have studied blockchain and the Energy Internet separately. Taking the IEEE Xplore database as an example, until July 2018, when the "Energy Internet" was searched as a keyword, a total of 1995 journals and magazines were obtained. When "blockchain" was searched as a keyword, a total of 713 conferences and journal articles were obtained. However, only 24 literatures were found that were related to both the Energy Internet and blockchain. Meanwhile, only a few 
reviews applied blockchain into a sustainable energy system. The application of blockchain technology in the energy field has just begun, and has great potential for development in the future. Therefore, it is meaningful to study a combination of the two. The organization of the paper is as follows: the blockchain technology is introduced in part 2; the definition and characteristics of the Energy Internet are introduced in part 3. In part 4, the compatibility of Energy Internet and blockchain technology is analyzed. Part 5 summarizes the research and several application scenarios of blockchain technology in the energy field; the challenges in the application of blockchain technology in the Energy Internet are presented in part 6.

\section{Blockchain}

\subsection{The Definition of Blockchain}

At present, blockchain has been widely concerned, but there is no accepted standard definition. Even so, all of the theories and researches are developing rapidly. It was pointed out by Melanie Swan in Blockchain: blueprint for a new economy [11] that blockchain is an open, transparent, and decentralized database. Harald [12] pointed out that blockchain is a technical solution for collectively maintaining a reliable database by decentralizing and detrusting. China Blockchain Technology and Application Development White Paper (2016) by the Ministry of Industry and Information Technology of China describes the concept of blockchain in a narrow sense and a broad sense. In a narrow sense, the blockchain is a kind of chained data structure in which data blocks are connected in a time sequence, and cryptography is used to guarantee the non-defective modification and unforgeability of the distributed ledger. The definition of this technology in a broad sense is that blockchain is a new application mode of computer technology such as distributed data storage, point-to-point transmission, consensus mechanisms, and encryption algorithms [13]. Yan et al. [7] Yuan and Wang [14], gives the following definition: blockchain technology is a new distributed infrastructure and computing paradigm. Based on a time-stamped "block and chain" data structure, this technology uses distributed node consensus algorithms to add and update data, cryptographic methods to secure data transmissions and access, and smart contracts made up of automated script code to program and manipulate the data [7]. This definition clarifies the operating mechanism of blockchain technology and its relatively comprehensive function.

\subsection{The Composition of Blockchain}

Blockchain is a data structure formed by a time sequence of blocks. The block is a collection of data containing related information and records, and it is the basic unit of blockchain [15] The data structure of the blockchain is mainly composed of a block header and a block body [16]: the block header mainly contains the hash value of the previous block, which is used to connect the previous block to ensure the integrity of the block chain; the block body contains the main information of the block (such as transaction information). This information together with the hash value of the previous block and the random number together form the hashed hash value of the current block. Its structure is shown in Figure 2 [17]. In the Bitcoin application scenario, each block data records system transaction data information (Trans in Figure 2) released by participating nodes within a certain time range. The transaction information includes sender and recipient identification, transaction amount, transaction time, and other additional information. In addition to the above transaction data, each data block also contains the block ID, timestamp (Timestamp in Figure 2), a connection relationship with a previous block (Reference in Figure 2), and so on. Then, blocks are interconnected into a chain that records all of the historical transaction information across the entire network. These data blocks are broadcast in real time to the entire shared network. Once they are confirmed and added to the chain, they are non-repudiation and hard to be tampered with, thus ensuring the transparency and reliability of the entire database [18]. 


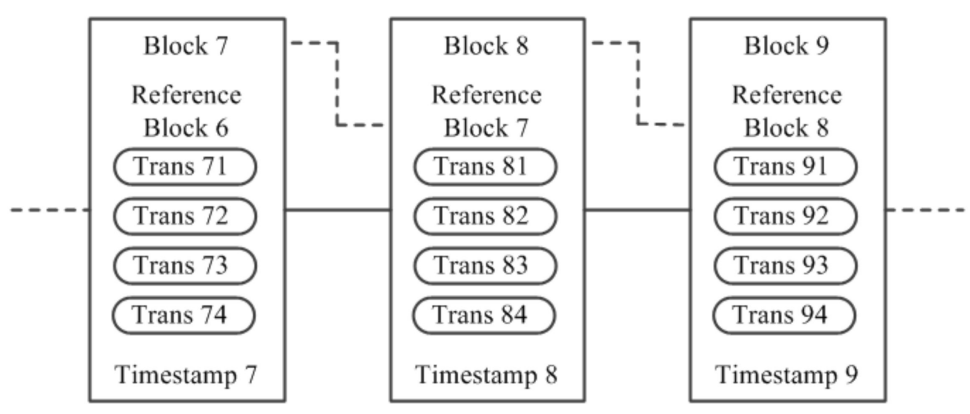

Figure 2. The composition of blockchain.

\subsection{The Technology Architecture of Blockchain}

The technology architecture of the blockchain is shown in Figure 3, which consists of the data layer, network layer, consensus layer, incentive layer, contract layer, and application layer [14]. The data layer contains the underlying data blocks and timestamps, etc. and stores all of the transaction data and information records in blockchain form; the network layer mainly includes peer-to-peer (P2P) network technology (also known as point-to-point transmission technology or peer-to-peer network technology), propagation mechanisms, and verification mechanisms. It will complete consensus algorithms, encrypted signatures, data storage, and so on; the consensus layer mainly includes a consensus mechanism, which enables nodes to reach consensus on the effectiveness of block data efficiently in the decentralized system where decision power is highly decentralized; the incentive layer integrates economic factors with blockchain technology, mainly including the issuance mechanism and distribution mechanism of economic incentives. The purpose of incentives is to attract participants to contribute to the computing power. The contract layer mainly encapsulates various script codes, algorithmic mechanisms, and smart contracts, and establishes regulated and auditable contract specifications.

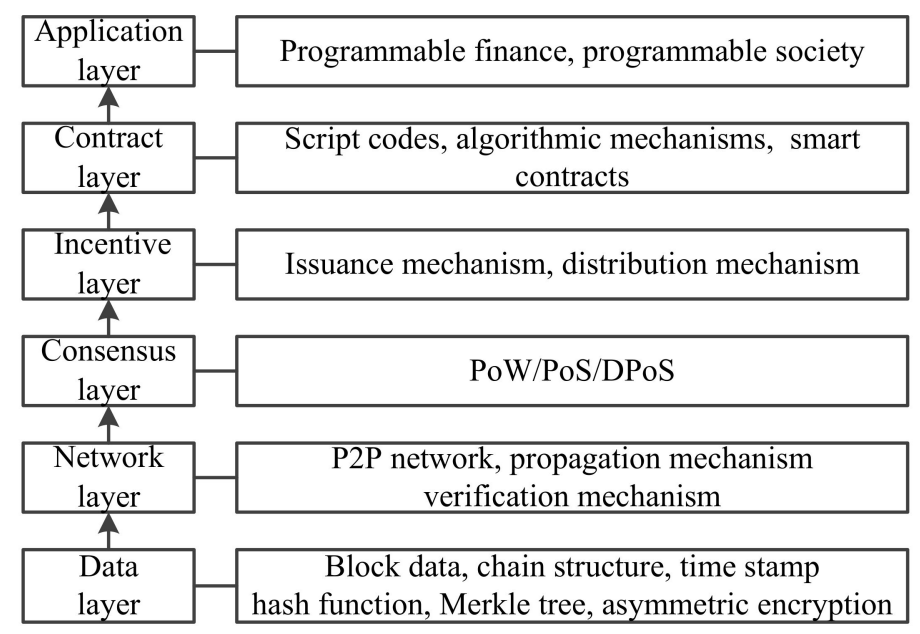

Figure 3. The technology architecture of blockchain. P2P: peer-to-peer.

\subsection{The Classification of Blockchain}

According to studies by Lei and Gang, blockchain falls into three categories [19]: public blockchain, consortium blockchain, and private blockchain. In the current application, Bitcoin and Ethereum are public blockchains, Blockchain Alliance R3 and Hyperledger are consortium blockchains, while Coin Science and Eris Industries, which specialize in providing blockchain services for companies, are private blockchains $[20,21]$. 
Table 1 compares the public chain, the consortium chain, and the private chain in terms of openness, write access, read access, anonymity, transaction speed, and decentralization [22-26].

Table 1. Comparison of different blockchain types.

\begin{tabular}{cccc}
\hline Items & Public Blockchain & Consortium Blockchain & Private Blockchain \\
\hline Openness & completely open & open to specific organizations and groups & open to an individual or an entity \\
Write access & anybody & specified multiple nodes & open to the public/be restricted by any degree \\
Read access & anybody & anybody & low \\
Anonymity & high & low & extremely fast \\
Transaction speed & slow & fast & partial decentralization \\
Decentralization & fully distributed & partial decentralization & \\
\hline
\end{tabular}

\subsection{Key Technologies of Blockchain}

Blockchain technology is not a single technology; it is a comprehensive technical system that integrates various research results. As illustrated in Figure 4, it mainly includes key technologies such as a consensus mechanism, encryption algorithms, the smart contract, and distributed data storage [27-30].

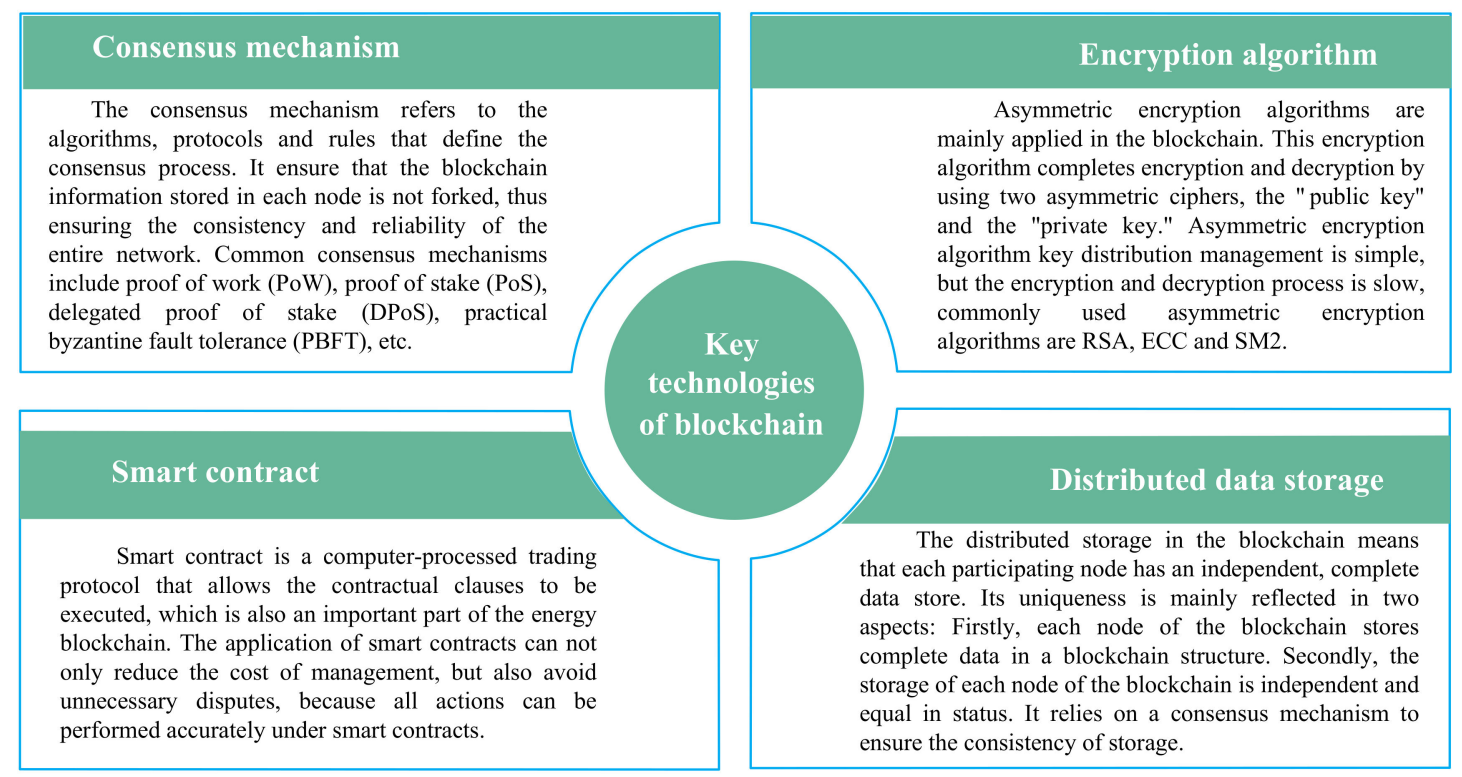

Figure 4. The key technologies of the blockchain.

\subsection{Characteristics of Blockchain}

The blockchain has five characteristics, as shown in Figure $5[7,19,31,32]$.

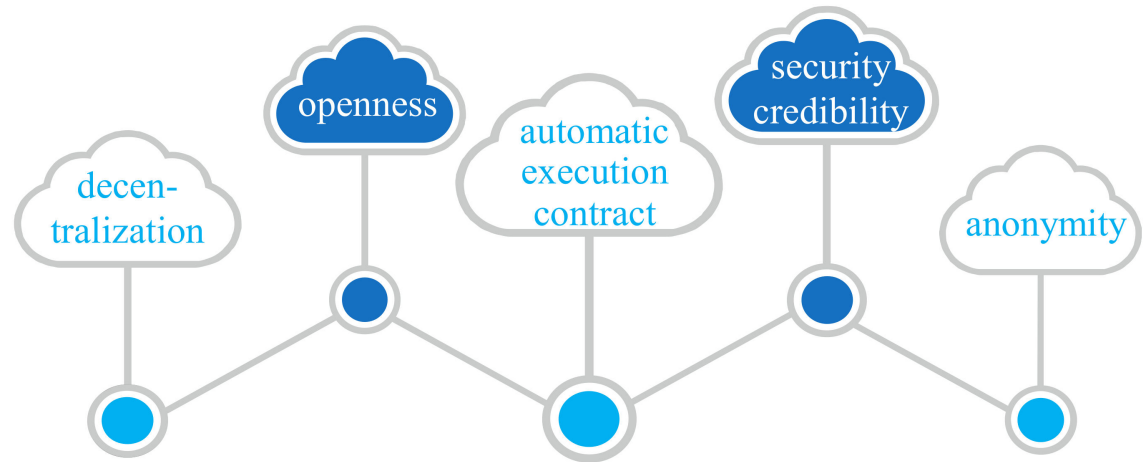

Figure 5. The characteristics of blockchain. 
(1) Decentralization. Since the blockchain system adopts the P2P networking mode, there is no mandatory control center. Every node in the network has equal status in the system. The data blocks generated are maintained by all of the nodes in the system. All of the nodes have recorded and stored transaction data, increasing the robustness of the database.

(2) Openness. The blockchain system uses trusted mathematical algorithms to regulate the behavior of transactions. The data exchange between nodes in the system does not require mutual trust. The operating rules are open and transparent. In addition to the private information of the node being encrypted in the system, the other data are open to all. Anyone can query the blockchain data information through the hash value of the block header, and the recorded information is redundantly backed up at multiple nodes. The update of information requires the mutual authentication of multiple nodes, which means that a node cannot deceive other nodes, so the information of the entire system is highly transparent.

(3) Automatic execution contract. The blockchain can be formed into smart contracts by writing code, which stipulates the obligations to be performed by each party in the contract and the conditions for the execution of the contract. The blockchain system automatically judges the execution conditions of the contract. When all of the determination conditions are satisfied, the blockchain system will automatically enforce the contract terms. On the one hand, this has increased the efficiency of contract execution, and more importantly, it has effectively ensured the implementation of the contract without the supervision of a strong third party [15].

(4) Traceability, data tamper protection, security, and credibility. Traceability means that the records added to the blockchain will be permanently stored, and trader information is bound to each transaction record in the blockchain. The complete transfer path of the object of transaction can be fully recorded and traced, which facilitates the supervision of the transaction [24]. Blockchain technology uses asymmetric cryptographic principles to encrypt data, and the powerful algorithm formed by the consensus algorithm is utilized to defend against external attacks and guarantee the non-destructive modification and unforgeability of blockchain data. Take Bitcoin blockchain as an example; data manipulation may only be implemented after controlling $51 \%$ of the computing power [33]. However, the cost of data tampering is much greater than the possible benefits, so the probability of participants trying to tamper with the data is extremely low, which gives the data in the blockchain higher security.

(5) Anonymity. Data exchange between nodes in a blockchain system follows a fixed algorithm, so both parties need not disclose their identities. Instead, the procedural rules in the blockchain are used to give each other trust.

\subsection{The Development and Application of Blockchain}

The development of blockchain can be divided into three stages. Blockchain 1.0 is characterized by a digital currency system, where Bitcoin is its initial form. Blockchain 2.0 takes the financial sector system as the main feature. Smart contracts emerged during Blockchain 2.0, and other types of assets were converted through smart contracts, supporting blockchain applications beyond the currency sector. Blockchain 3.0 is mainly characterized by the programmable society. Based on existing infrastructure such as Internet and mobile communications, the application of the blockchain gradually extends to all aspects of society and life, such as science, education, culture, and other fields [34,35].

All countries in the world are paying more attention to the development of blockchain technology. The blockchain market size is expected to grow from USD 241.9 Million in 2016 to USD 7683.7 Million by 2022 , at a compound annual growth rate of $79.6 \%$ [36]. The business of this type of supplier includes payments, documentation, exchanges, and other programs designed to increase the efficiency of business operations. In January 2016, the British government issued a research report of "Blockchain: distributed ledger technology", which was the first report on applications of blockchain technology at the national level, conducting a comprehensive analysis and giving research proposals. The report proposed that the blockchain should be included in the United Kingdom (UK)'s national strategy and 
promoted its application in areas such as finance and energy [37]. In February 2016, the European Commission placed the cryptocurrency at the top of the fast-growing target area. This move promoted the research of various institutions on digital currency policies. In May 2016, Japan approved the digital currency Supervision Act for the first time and defined it as property. Japan has established the first blockchain industry organization, called the blockchain cooperation alliance (BCCC). In June 2016, the United States (US) Department of Homeland Security issued subsidies to six companies dedicated to the development of the government's blockchain applications. In December 2016, the "The 13th Five-Year Plan for National Informatization" which was issued by the State Council of China includes the blockchain technology [38]. In April 2017, the Hangzhou Municipal Government hosted the 2017 Global Blockchain Finance (Hangzhou) Summit, which was the first time that China hosted the blockchain summit from the government level. At this conference, Hangzhou launched China's first blockchain industrial park, and the settled enterprises can enjoy preferential policies such as tax incentives and awards for scientific and technological achievements.

Countries in the world have begun to explore industry applications in many areas, such as digital currency, securities trading, cross-border payment, identification, academic certification, love donation, etc. However, on the global scale, no new mature blockchain applications have emerged except Bitcoin. China is currently at the same level as the world. The US Nasdaq took the lead in introducing the blockchain technology-based securities trading platform Linq in December 2015 [39], becoming an important milestone in the decentralization trend of financial and securities markets. Based on the BaaS (Blockchain as a service) service launched by Azure, a Microsoft cloud service platform, startup R3 CEV has signed blockchain cooperation projects with over 40 major banking institutions including HSBC, Goldman Sachs, and Citibank, and is dedicated to the development of banking industry blockchain industry standards and protocols. The Canadian ATB Financial Bank successfully used blockchain technology to send 1000 Canadian dollars to Germany in 20 s, which generally takes more than two working days to complete through traditional payment methods. According to estimates by McKinsey and Co., worldwide application of blockchain technology in cross-border payment and settlement can reduce transaction costs from approximately $\$ 26$ to $\$ 15$ per transaction [40]. The UK Everledger uses diamond 4C information (color, cut, purity, and carat) and other characteristic data to generate a unique identification for each diamond for identification. MIT developed an academic certification system based on blockchain technology. Alipay cooperated with public foundation, and on its caring donation platform set up the first public welfare projects, based on the blockchain can guarantee the authenticity of public data from the technology, as well as save information disclosure cost. Alipay cooperated with the Charity Foundation to set up the first blockchain-based public welfare project on its love donation platform, which can technically protect the authenticity of public interest data and save on the cost of information disclosure.

\section{Energy Internet}

\subsection{Introduction and the Definition of Energy Internet}

With the depletion of traditional fossil energy and the increasingly serious environmental problems, the development mode of energy based on traditional fossil energy is difficult to sustain. It is a general trend to replace fossil energy with clean and sustainable energy. At present, although research in the field of sustainable energy has made some progress, the relatively mature technologies such as wind energy and solar energy have the problems of decentralized geographical distribution, low management and utilization rates, and high energy conversion costs, leading to great restrictions on the use of new energy in large-scale applications and marketization [41]. In 2008, "Future Renewable Power Energy Transmission and Management System", the project of National Science Foundation (NSF), clearly proposed the concept of the Energy Internet [42]. This academic concept points out that the Energy Internet is a new type of power grid structure based on renewable energy generation, distributed energy storage devices, and the existing Internet. 
It also argues that the Energy Internet will be the main research direction in the energy sector to get rid of existing difficulties. Rifkin [43] stated in the book entitled "The Third Industrial Revolution" that with the depletion of traditional fuels and the gradual deterioration of the global environment, humanity will enter into an Energy Internet system that combines new energy technologies and new information technologies. Japanese researchers have focused on the development of the digital power grid system, and the Japan Digital Grid Alliance has proposed an Energy Internet based on "power routers". The preliminary definition of the Energy Internet is given in Dong's et al. [44]: the Energy Internet is a closed-loop, complex, multi-network flow system in which distributed renewable energy is the primary energy source, and is closely coupled with other systems such as natural gas networks and transportation networks. Its core is the power system, and it is based on Internet and other cutting-edge information technologies. The definition of the Energy Internet given in Ma's et al. [45] is more specific: it is centered on the power system, with the smart grid as its backbone, and linked by the Internet, big data, cloud computing, and other leading information and communication technologies. With the comprehensive use of advanced power electronics and intelligent management technologies, it is the next-generation energy system that can realize the integration of horizontal, multi-source, complementary, vertical source-net-neutron-to-storage coordination energy and information. Meanwhile, it has the characteristics of being a flatter platform that has a commercial and user service facing society.

Compared to the existing power grids, the Energy Internet involves a wider variety of energy forms and broader participants, and it changes the interactive mode of information so as to build a new type of energy supply system with multi-energy complementary and highly integrated energy and information [46]. So far, the research on the Energy Internet is still at the stage of theoretical research and architecture design. True running of the Energy Internet is still rare.

\subsection{Characteristics of Energy Internet}

The Energy Internet has features such as accurate measurement, wide-area multi-source cooperation, intelligent control, and open trading [45,47], as shown in Figure 6.

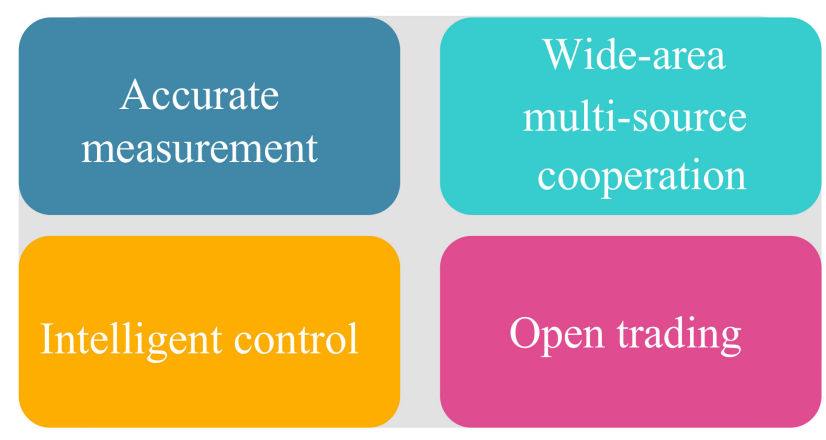

Figure 6. The characteristics of the Energy Internet.

\section{(1) Accurate measurement}

Measurement is the basis for controlling the operating status of various energy systems and is the source of energy informatization. In addition to accurate measurement, the Energy Internet must also address the issue of consensus trust between different participants in the measurement data.

(2) Wide-area multi-source cooperation

The Energy Internet has the characteristics of wide coverage, many participants, and high reliability. Multi-source cooperation includes both the coordination of the planning operation of large-scale energy production bases and the cooperation in energy transmission and terminal 
energy utilization. Participants can achieve consensus through coordination and achieve the goal of maximizing profits.

(3) Intelligent control

Intelligent algorithms such as big data analysis and machine learning will become important technical support for the Energy Internet to cope with the use of a large number of distributed energy sources in the Energy Internet. The entire process from energy production to use relies on intelligent control technology to achieve flexible and efficient power conversion and optimize the energy transmission path, thereby improving the system's operating efficiency and reliability.

(4) Open trading

Energy Internet is the infrastructure of modern society, including both large-scale centralized grids and distributed micro energy grids. All kinds of energy can access the Internet without discrimination. Energy producers can also be energy users, and the users' participation is greatly enhanced. Whenever and wherever, the Energy Internet supports various energy services, supporting demand response, ancillary services, and electricity purchase and sales services. By reducing the peaks and valleys of the Energy Internet, its operating efficiency will be improved.

\section{Compatibility of Energy Internet and Blockchain Technology}

The foundation of blockchain technology applied to the Energy Internet is that the two should be compatible; their compatibility comparisons $[15,28,46]$ are shown in Table 2.

Table 2. Comparison of compatibility between blockchains and the Energy Internet.

\begin{tabular}{|c|c|c|}
\hline Characteristics & Blockchains & Energy Internet \\
\hline Decentralization & $\begin{array}{l}\text { There is no control center for the } \\
\text { operation. Each node saves all of } \\
\text { the information of the blockchains, } \\
\text { and the peers have equal rights } \\
\text { and obligations. The operation of } \\
\text { the system is decentralized, } \\
\text { and equal decision-making is } \\
\text { made by each node. }\end{array}$ & $\begin{array}{l}\text { Include more distributed energy and } \\
\text { microgrids, which can be either consumers or } \\
\text { producers. The operation of the system will } \\
\text { change the trust center decision model of } \\
\text { traditional energy networks. The participants } \\
\text { in the network can independently manage } \\
\text { their own energy production, consumption, } \\
\text { and transactions. }\end{array}$ \\
\hline Interconnected autonomy & $\begin{array}{l}\text { The high degree of interconnection } \\
\text { between nodes ensures that each } \\
\text { node can read, write, and verify } \\
\text { blocks at any time. The blockchain } \\
\text { system has no control center and } \\
\text { is operated and maintained by all } \\
\text { of the nodes in the network. }\end{array}$ & $\begin{array}{l}\text { Each system module can realize the full } \\
\text { interconnection of energy and information. } \\
\text { It emphasizes the automatic scheduling and } \\
\text { ecological operation of the system, with high } \\
\text { security and economy. }\end{array}$ \\
\hline Openness & $\begin{array}{l}\text { It provides a wide range of } \\
\text { network interfaces. Each body can } \\
\text { participate in the operation and } \\
\text { maintenance of the system } \\
\text { independently and become } \\
\text { a component of the decentralized } \\
\text { database. And it can establish } \\
\text { a fair and open market mechanism } \\
\text { by using blockchain technology. }\end{array}$ & $\begin{array}{l}\text { The network structure is open to all types of } \\
\text { entities, thus providing a platform for } \\
\text { physical information exchange for the energy } \\
\text { industry and other industries. It is also } \\
\text { conducive to the establishment of } \\
\text { a market-oriented mechanism. }\end{array}$ \\
\hline Intelligence & $\begin{array}{l}\text { Automatic execution of contracts } \\
\text { through smart contracts or } \\
\text { "programmable currency". }\end{array}$ & $\begin{array}{l}\text { Automated transactions of participating } \\
\text { parties are everywhere, and transactions } \\
\text { are intelligent. }\end{array}$ \\
\hline
\end{tabular}

Blockchain technology and the Energy Internet both reflect the concepts of decentralization, interconnected autonomy, openness, and intelligence. Applying blockchain technology to the Energy Internet can solve some of the bottlenecks in the development of the Energy Internet. For example, because the Energy Internet has many participating nodes, the trust problem of distributed decision-making 
can be the key issue, while the blockchain technology solves exactly the trust problem of the centerless decision-making organization. The energy router is one of the key technologies of the Energy Internet. It can obtain the state information of the energy flow through the information flow, thereby realizing functions such as scheduling and control. The energy router can be developed by using the blockchain technology. Therefore, it is feasible to use blockchain technology for Energy Internet systems.

\section{Application Scenarios and Practice of Blockchain in Energy Internet}

\subsection{Application Scenarios of Blockchain in Energy Internet}

This section introduces the application scenarios of blockchain in the Energy Internet from seven aspects (as shown in Figure 7).

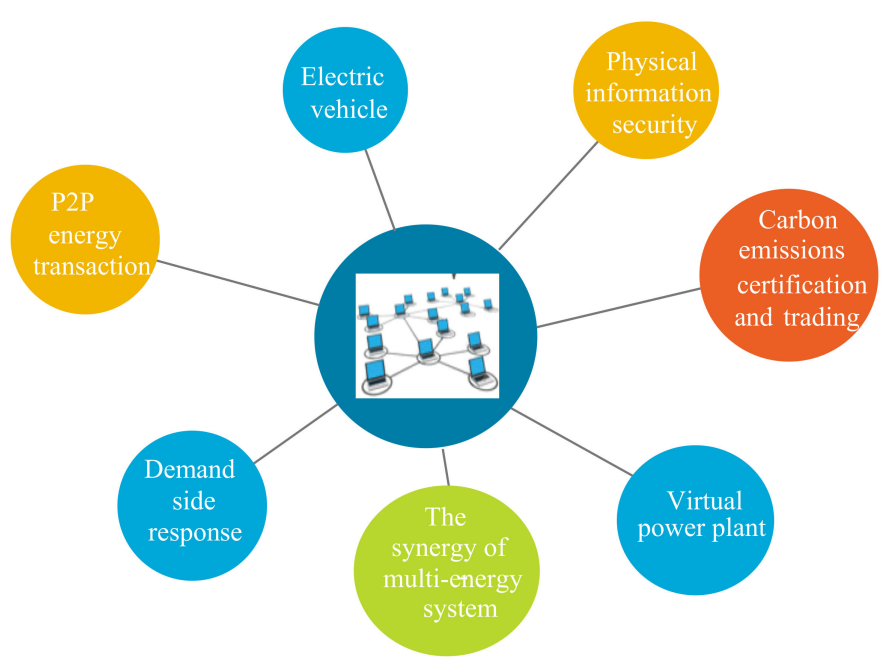

Figure 7. Applications of blockchain in the Energy Internet.

\subsubsection{P2P Energy Transaction}

Traditional energy trading is managed through a centralized organization. With the access of a large number of consumers, the Energy Internet has become more complicated. If a centralized organization is established, there are problems such as high operating costs and poor information security. If there is no centralized management organization, there will be the problem of distrust of the trading entity. The introduction of blockchain technology into energy trading can overcome these problems. The blockchain-based P2P energy trading model can provide an efficient, inexpensive, open, and trustworthy trading platform for the Energy Internet. Figure 8 shows the power trading process based on blockchain. 


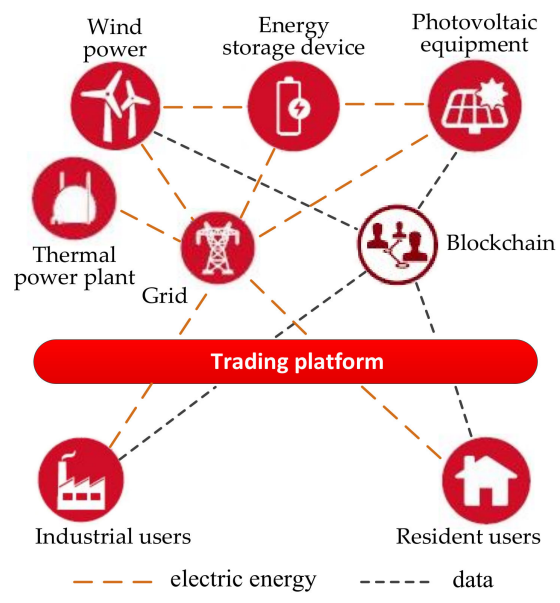

Figure 8. Blockchain-based power trading process [48].

Aitzhan and Svetinovic [49] applies multi-signature technology, blockchain, and anonymous information flow in distributed energy transactions, and proposes a solution to ensure transaction security when third parties are not trusted in a distributed smart grid. Burger and Kuhlmann [50] analyzed and prospected the application of blockchain in energy trading, and proposed that Enercoin (a digital currency similar to Bitcoin) ought to replace the Euro for energy trading. It also qualitatively described the changes in demand for Enercoin caused by distributed power and load changes and the impacts of the European Central Bank (ECB)'s currency adjustment policy. The conversion relationship among Enercoin and Euro between the central bank, commercial bank, and market participants is shown in Figure 9. After Euro is converted to Enercoin, it can be circulated in the trading market.

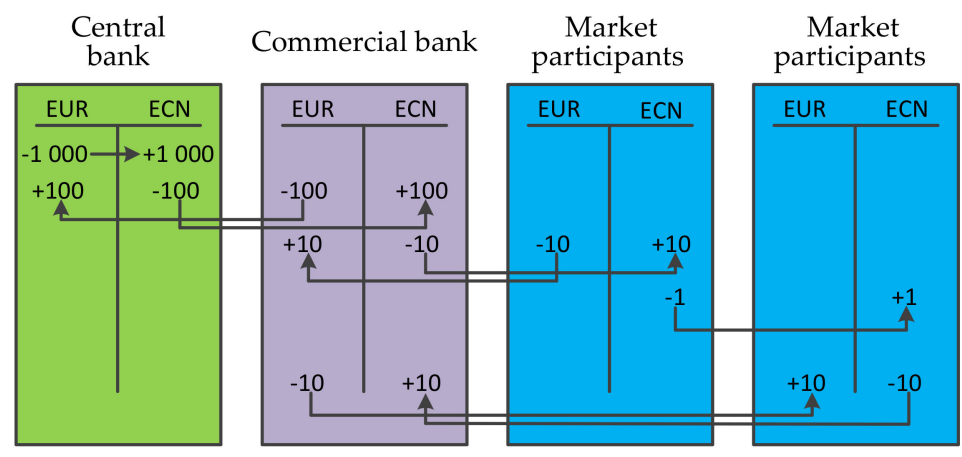

Figure 9. Enercoin's cycle diagram [24].

These studies all regard energy as a general commodity, and do not consider the particularity of energy commodities. In fact, the energy trading cannot be separated from certain supervision, so these research studies are not enough to solve the practical application of energy trading. Mannaro et al. [51] considered the security of grid transactions, proposed a method to manage electricity trading with weak centralization, used blockchain technology to store power trading information in the form of smart contracts, and automatically performed fund transfer. In addition, there is also a need for a central authority with limited powers to conduct security checks and block management on transactions that have been reached. Sabounchi and Wei [52] analyzed the difficulties that need to be solved to implement energy trading in the Energy Internet, and presented a three-tier (transaction layer, extension layer, and blockchain layer) energy trading framework based on blockchain technology, and introduced a weak centralized management approach to deal with the problems caused by decentralization. The weak central institution is regarded as a special node in the blockchain network, 
and it conducts necessary supervision on the participants involved in energy transactions, trading activities, etc., to ensure the smooth progress of transactions.

\subsubsection{Electric Vehicle}

In the area of advocating green travel and energy conservation, the widespread use of electric vehicles will be one of the effective solutions to environmental problems. However, electric car users are facing the difficulty of charging. Compared to gas stations, the number of charging piles for electric vehicles is still small, which is the main bottleneck restricting the widespread use of electric vehicles. At present, there are a large number of electric vehicles charging pile operators and payment platforms; however, the charging standards are not uniform, which brings great inconvenience to users. The unified bottom payment platform built by the blockchain technology is more easily accepted by the public. In addition, the on-time lease of private charging piles based on smart contracts and distributed general ledger technology can also alleviate the status of a small number of charging piles [53].

In the field of interaction between electric vehicles and the electric grid, there is a lack of V2G incentives, and the use of power battery cascades cannot guarantee the quality of batteries. For example, Energy Blockchain Labs proposed a blockchain-based solution based on the virtual currency incentive mechanism for the electric vehicle (EV)'s V2G (vehicle to grid) automatic response, battery cell lifecycle data blockchain storage, and certification.

In California, eMotorWerks provided an application called JuiceNet [54], which was a market-driven IoT platform. This blockchain platform allows the owners of charging piles to use JuiceNet to lease the time of charging piles to electric vehicle drivers. This is equivalent to increasing the number of charging posts. At the same time, the owners of charging piles can receive corresponding economic compensation. JuiceNet uses blockchain technology to store and process data in real time, making people connect and share charging services in a safe and convenient way. In addition, any EV driver can download the JuiceNet app, view the available charging devices on the map, and navigate to a nearby charging station for charging. Figure 10 shows the Internet of Things platform JuiceNet.

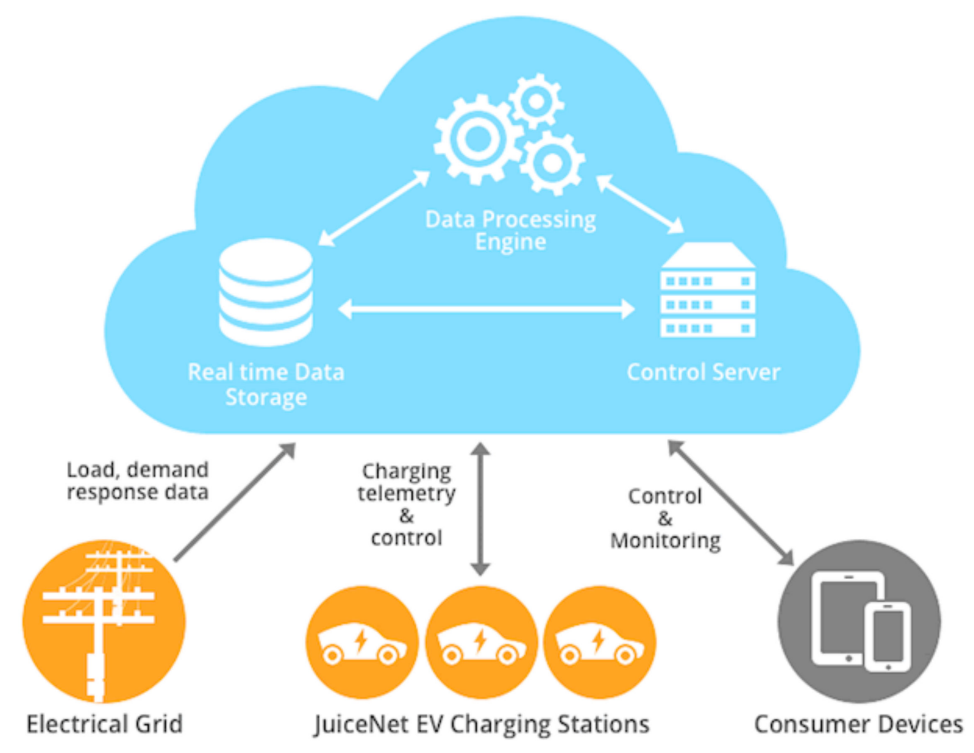

Figure 10. JuiceNet Platform [55].

\subsubsection{Physical Information Security}

The security of the power information system is extremely important. Accurate information will guide the system to make reasonable decisions. Once the information system is damaged or attacked, the wrong information may have catastrophic effects on the system. At present, the main security 
protection method for power grid companies is to build dedicated communication lines to isolate internal and external networks. However, using the data of the information collection equipment in the dedicated line transmission system will increase the construction cost of the system, while the use of power line carriers or public networks for information transmission or exchange is vulnerable to interference and attacks. In 2010, people discovered the first Stuxnet, which was a computer virus specifically targeted at industrial control systems. It could infiltrate a computer network that is isolated from the external network through infected USB devices, and thus attacks the corporate internal network. In 2015, Ukraine's electricity information system was hacked, resulting in a massive blackout [56]. Therefore, the ability of energy systems to resist cyber-attacks needs to be strengthened.

The blockchain is used as the bottom of the information system in the Energy Internet. The characteristics of blockchain decentralization, high-redundancy storage, high security, and privacy protection help solve some of the security problems faced by information and physical systems. At present, there are few studies on the use of blockchain technology to solve security problems in the Energy Internet. Ding et al. [28] analyzes the security challenges faced by blockchains in the Energy Internet from the perspectives of the loss of private keys, privacy leaks, and protocol attacks. It also proposes a security protection system that builds energy blockchain from three aspects: structural security, ontological security, and management security. Security protection runs throughout the entire life cycle of the energy blockchain information system, so as to effectively meet the development needs of the future energy blockchain.

\subsubsection{Carbon Emissions Certification and Trading}

The rapid increase in the concentration of greenhouse gases has led to the deterioration of the global climate. In order to promote energy conservation and emission reduction in various countries, the United Nations has established the certification and trading mechanism for carbon dioxide emission rights through the Kyoto Protocol [57], using economic means to achieve the purpose of controlling emissions. According to the carbon emissions of various industries, China allocates a certain amount of carbon emission rights to enterprises that produce emissions. Companies that emit more than their allowances can purchase emission rights from companies that have a balance of emission rights, or they will be fined. On the contrary, enterprises with surplus emission rights can earn profits by selling emission rights.

At present, the carbon emission market is facing problems such as large workload of emission quota certifications and difficulty in tracing transaction data. Blockchain technology can provide an intelligent management platform for the certification and trading of carbon emission rights, as shown in Figure 11. Through this technology, every ton of carbon and all transaction information can be traced, avoiding tampering and information asymmetry. China Certified Emission Reductions (CCER) will be traded in the form of digital assets "carbon tickets". Each carbon ticket has a unique ID, time stamped and recorded in blockchain. Carbon trading will be performed automatically through smart contracts. 


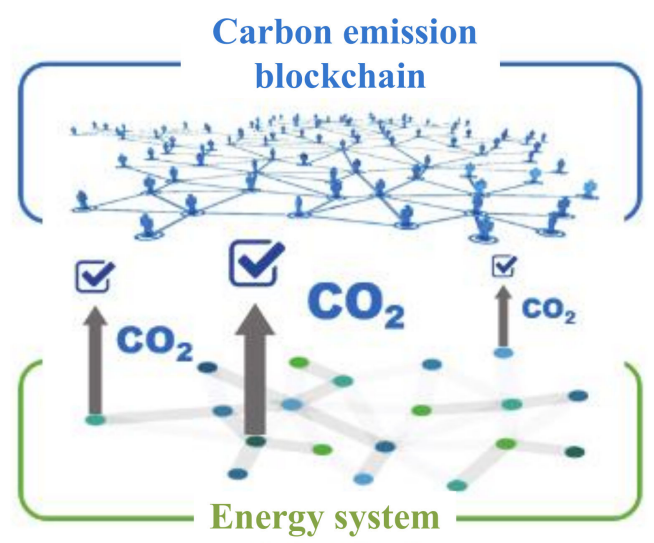

Figure 11. The application of blockchain in carbon emission permits certification. [15]

At the same time, the traditional carbon asset development process takes a long time, involving companies, government regulators, carbon asset exchanges, third-party verification and certification agencies, and so on. The average development time is more than one year, and each participating node will have a large number of file transfers, which are prone to errors. The blockchain can also solve this problem. IBM and China's Energy Blockchain Labs will build the world's first blockchain-based "green asset management platform" to support low-carbon emission technologies. The platform will dramatically shorten the development cycle of carbon dioxide assets and reduce the development cost of carbon dioxide assets by $20 \%$ to $30 \%$ [58].

\subsubsection{Virtual Power Plant}

The virtual power plant (VPP) is an important branch of the Energy Internet. The Energy Internet contains a large number of distributed green power supplies. The green power supplies are characterized by randomness, volatility, and intermit entity. VPP can use a virtual control center to aggregate distributed power resources (DERs) and distributed energy storage systems for centralized management and unified scheduling, resulting in a combined structure similar to traditional power plants [59]. It plays an important role in the aggregation of distributed generation resources and the establishment of virtual power resource transactions.

Blockchain technology has the characteristics of decentralization and mutual complementarity, which is similar to the geographical dispersion and scheduling of virtual power plants. However, transaction costs are higher between virtual power plants and users. Moreover, the profit distribution mechanism of each VPP is not open. The two-way choice of information symmetry cannot be formed between distributed energy and VPP, which increases the credit cost in the transaction process. The blockchain technology has its advantages in transaction applications because of its own characteristics, and can provide a transparent, fair, reliable, and low-cost trading platform for virtual power plants [60]. Therefore, blockchain technology is suitable for use in VPP [61].

Wei and Yue [62] introduced the blockchain technology into VPP for the existing problems in the VPP model, and proposed an improved VPP operation and scheduling model. This model has advantages in the consumption of coal, greenhouse gas emissions, and economic costs over the original VPP operating model. It also uses the cryptographic features of the blockchain itself to enable the virtual power plant to obtain a greater degree of information security. Table 3 shows the comparison between a conventional VPP and a VPP based on energy blockchain. 
Table 3. Comparison between a conventional virtual power plant (VPP) and a VPP based on energy blockchain.

\begin{tabular}{ccc}
\hline & Conventional VPP & VPP Based on Energy Blockchain \\
\hline Information transparency & Low & High \\
System information security & Low & High \\
Transaction cost & Low & High \\
Demand-side information & Non-real time & Real time \\
Coal consumption & Low & High \\
Greenhouse gas emissions & Low & High \\
\hline
\end{tabular}

\subsubsection{The Synergy of the Multi-Energy System}

Through energy conversion equipment, energy, electricity, heat, natural gas, and other energy sources in the Energy Internet can realize flexible flow in different physical systems, achieve flexible storage and a cascading utilization of energy, and significantly improve energy conversion and utilization efficiency [63]. However, with the different physical properties of different energy sources, it is difficult to establish a centralized dispatching organization for the operation and management of the Energy Internet.

Mihaylov et al. [64] proposed an idea of using blockchain technology for settlement in multi-energy complementary systems. Zhang Ning, Wang Yi, and others proposed using blockchain to provide a decentralized system platform for multi-energy systems [15]. Blockchains are used to record real-time production information and costs for different energy systems. When there is a trans-energy market, the transactions between multiple energy systems and their price information can be recorded. On this basis, the marginal prices of various energy sources in different regions can be generated in real time (e.g., node electricity price, node gas price, node thermal price). Different energy systems can optimize the operation of their systems through the marginal price information in the blockchain, or execute automatic scheduling instructions and perform energy cost settlements based on marginal price information by signing smart contracts.

Ming and Jun [46] proposed a mechanism framework that uses blockchain technology to implement distributed decision-making and collaborative autonomous operation of Energy Internet systems. Based on the distributed operation decision mechanism of the blockchain system, the multi-module collaborative autonomous mode of the Energy Internet and its controlled flow are proposed. Taking the three modules of energy utilization, transmission, and supply as examples, the reference also elaborates the multi-module collaborative autonomous mode of the Energy Internet and its control flow under the blockchain framework. This model is expected to provide a viable technology choice for the decentralized decision-making and coordinated autonomy of the Energy Internet.

\subsubsection{Demand Side Response}

In recent years, there have been some research results on the supply of auxiliary services on the demand side [65-67]. The relevant literature shows that demand response services are one of the most economical technical means to meet the real-time backup of regional power grids, and can even provide rapid response services [68]. With the gradual liberalization of China's electricity-selling market, more trading entities will emerge in the electricity market. However, during the actual operation and implementation of demand response services, the existing market mechanisms still have regulatory problems in terms of supervision, accounting, etc. In the large-scale implementation of demand response services, it will be difficult to achieve low-cost, large-scale participation in user interaction if centralized management and control methods are still used [69]. Blockchain technology adopts the method of accounting for distributed general ledgers. It can not only solve the problem of false accounting and wrong accounting in automatic demand response services, it can also 
establish a complete set of traceability systems and supervise the settlement of each participating transaction fund.

A joint study by the Zurich Federal Institute of Science and Technology and the University of Michigan put demand side resources as a means of up-reserve and down-reserve. Through direct control, it controls its participation in the operation of the ancillary service market [70]. Mohsenian-Rad et al. [71] used game theory to establish a distributed automatic demand side management strategy to protect users' privacy. Yang and Zhang [72] proposed an automatic demand response (ADR) method for an energy local network (ELN) energy storage system based on blockchain technology. Using the congestion price algorithm, a decentralized automatic demand response criterion is developed. The responding entity can rely on the established criteria to autonomously respond to system compensation requirements. On this basis, a smart contract between responding entities was established to ensure the efficient execution of energy transactions and benefit distribution. Bin and Chao [73] proposed an application scheme based on blockchain technology with the analysis of the demand for existing automatic demand response services. Moreover, it also analyzed the key issues of blockchain in the automatic demand response system from workload proof mechanisms, interconnection consensus, smart contracts, information security, and so on.

Finland's Fortum has planned to implement a blockchain-based smart load demand-side response project. Based on the real-time information of the power generation market, blockchain technology is used to solve problems such as plan determination, load assessment, and income distribution, and mobilize smart appliances to dynamically participate in the load-side response [74].

\subsection{Practical Applications}

The US energy company LO3 Energy and the blockchain company ConsenSys launched the TransActive Grid project in the Gowanus and Park Slope neighborhoods of Brooklyn, and the Siemens Digital Grid later joined the project. This is a blockchain-based micropower-trading platform composed of 10 households. Photovoltaic power generation equipment is installed on the roof of every household, forming a small blockchain system with 10 nodes. Each home can be either a consumer or a producer. Each node can sell excess power directly to neighbors, and the transaction process does not require the participation of power companies [75]. The EU Scanergy project also intends to establish a small user green power trading system NRG-X-Change based on the TransActive Grid model. The project envisages detecting the user's production and consumption status every $15 \mathrm{~min}$ in the trading system, and then making settlement transactions based on NRG coins [76].

German electricity supplier RWE and blockchain company Slock have collaborated on electric vehicle charging projects [77]. They developed an electric vehicle charging payment system, Block Charge, based on blockchain technology; the system uses blockchain smart contracts to verify user identities. Then, users will no longer sign contracts with companies or individuals, and instead use Ethereum smart contracts to sign contracts. After the user agrees with the smart contract, he can trade with the charging station. They also developed a product called Share and Charge that enables the sharing of charging piles and completes the automated management of certification, charging, and payment under this application scenario. In the latest test version, this product allowed private users to share personal charging stations via the mobile phone application (APP) in addition to their partner RWE charging stations. These two projects also make the wide application of electric vehicles more economical and feasible.

Filament of the United States in Australia uses blockchain technology and Internet of Things (IoT) technologies to upgrade transmission equipment in the traditional grid. The utility pole is constructed into a digital node of IoT, and a set of detection devices called "taps" is arranged on the nodes, and a corresponding communication mechanism is established for these detection devices based on the blockchain technology. The detection device can detect the operating status of the grid node and spread the data to the entire network via the blockchain in a P2P manner. This information is available to the government, media, power grid maintenance companies, and users 
to ensure the safe management of electricity and its equipment [78]. In addition, Filament and the United States IDEO Colab co-developed a solar panel device based on blockchain technology. Using Filament's interface, it can directly contact the Nasdaq platform to generate renewable energy in real-time. Renewable energy certificates/subsidies (RECs) are generated in real-time while tracking the generation of electricity generation, thereby combining the three major applications of solar power generation, new energy subsidies, and electricity payments.

At the EMART Energy Fair held in Amsterdam in November 2016, 23 energy-trading companies entered into an alliance to develop and use energy blockchain, of which Yuso and Priogen Trading used Enerchain, which was developed by PONTON, as a trading tool [79]. Enerchain software allows the use of encryption technology trading organizations to send orders anonymously, and trading agencies can view the order. The entire process is not a centralized market operated by third parties.

$\mathrm{Yu}$ and Huateng established the world's first energy blockchain laboratory as a founding partner in May [80], and they also promoted the Energy Blockchain Labs as the world's first industrial blockchain application company to join the Hyperledger Project and the Linux Foundation. The State Grid Zhejiang Electric Power Company Electric Power Research Institute has undertaken the first blockchain project of the State Grid Corporation of China, and is the earliest research institute that applies blockchain to the Energy Internet.

In January 2018, Panda Green Energy, Huawei, and the New Energy Exchange held a meeting in Shenzhen to officially launch the blockchain plan. Panda Green Energy entrusted the New Energy Exchange to develop a smart power station blockchain management system and Pandacoin. Pandacoin is a digital currency that uses the Panda Power Station jointly built by the Chinese government and the United Nations as an asset carrier. Investors around the world can subscribe and trade new energy assets such as global solar energy, wind power, and hydropower through Panda Currency [81].

\section{Challenges of Blockchain Technology Applied to Energy Internet}

(1) Blockchain technology still has some bottlenecks

As the number of access blockchain nodes increases, the efficiency of its consensus algorithm will decrease and the response speed will decrease. Blockchain transaction records and related information require all participating actors to perform synchronous storage, which requires large-capacity storage systems (both hardware and software) for support. In addition, this behavior of all nodes in the blockchain participating in accounting consumes a lot of resources. Taking Bitcoin as an example, the number of global Bitcoin transactions was approximately 30 million in 2017. According to data published by Diginominist, in order to certify the 30 million transactions, a total of 30 billion $\mathrm{kWh}$ was consumed, accounting for $0.13 \%$ of global power consumption [82]. Plattsburgh, New York has imposed an 18-month moratorium on Bitcoin mining because of the huge city electricity consumed by the exploitation of commercial cryptocurrency [83].

(2) The reliability and security of blockchain technology applied to the complex Energy Internet is not enough

The energy system is a complex physical system. The application of blockchain technology needs to fully consider the physical laws of the energy system. The application of mature blockchain technology is mainly based on value transmission. However, in the blockchain applied to the Energy Internet, there is energy transmission in addition to value transmission, and value transmission is carried out around the energy transmission. Energy is transmitted from one end to the other via a physical network, such as the transmission of electricity through the power grid, or the transfer of natural gas through pipelines. There is a loss in the conversion between different types of energy sources and in the energy transmission process, which all face the problem of how the physical world and the digital world are mapped. The concentration of the energy industry is relatively high. Over $51 \%$ of the computing resources in the Energy Internet are likely to be controlled by a certain interest group. At this time, the information security of the blockchain will be greatly threatened. 
At present, the application of blockchain technology in the energy field is still in its infancy, and the potential risks of blockchain application in the Energy Internet are difficult to prevent.

(3) The standardization and supervision mechanisms of blockchain technology need to be improved

As a new technology, except bitcoin, the other applications of Blockchain technology are just beginning, and the relevant norms and standards have not yet been fully established. Energy is an extremely special commodity, and its trading and operation need strict supervision. However, relevant laws and regulatory measures are still lacking. The application of blockchain technology to the Energy Internet is not only technically safe and reliable, it is also related to government related policies.

(4) There is a talent shortage in blockchain

Blockchain technology has been emerging for almost a decade, but it has been widely considered by people for only three years or so. Researchers have been working on blockchain technology for a shorter period of time. According to the Boss Direct Employment Research Institute, the job requirements related to blockchain have grown rapidly since the second half of 2017. As of February 2018, blockchain-related posts accounted for $0.41 \%$ of the total number of Internet industry posts [84]. However, the supply and demand ratio of professional blockchain technology talents is only 0.15 , and the supply is seriously insufficient. The industry's increasing demand for blockchain talents and the training of blockchain technicians cannot be delayed.

\section{Conclusions}

This paper introduces the compatibility research of blockchain technology and the Energy Internet. According to the results and the main findings in the literature review, the main contributions of this paper can be summarized as follows:

- The reasons why the blockchain technology is hot all over the world can be derived. The reason is that it can establish reliable trust between nodes in the network, making the value transfer process independent of the central node. The addition or update of network data is accomplished by a distributed node consensus algorithm, which is transparent and can protect privacy. At the same time, the use of encryption algorithms ensures the security of data. Blockchain technology is an operating mechanism that increases the efficiency of value exchange and reduces costs.

- The Energy Internet involves more energy forms and participants. It is a new type of energy supply system with multi-energy complementary and highly integrated energy and information, and also provides a possible solution for flexible access to-and the large-scale utilization of - various types of clean energy.

- There is a good compatibility between the Energy Internet and blockchain technology. The application of blockchain technology to the Energy Internet provides a good opportunity for the development of the Energy Internet, since it can solve many of the problems that hinder the development of the Energy Internet, such as the control and management of distributed sustainable energy forms. Many practical scenarios have been summarized in this paper, and the challenges are also summarized.

Compared with the recent literature review, the main contributions of this paper are to analyze the compatibility of the Energy Internet and blockchain technology, and introduce the application scenarios and practices of blockchain in the Energy Internet. Finally, the challenges of applying blockchain to the Energy Internet were raised. The purpose of this paper is to provide a current research status for Energy Internet researchers so that they can start their own studies and promote the practical application of blockchain in the Energy Internet. Blockchain technology has great application prospects in the energy field, but the current research is still in an early stage. Although researchers and companies have made some small-scale attempts, there are still many challenges in the applications, such as excessive power consumption and a lack of regulatory mechanisms. How to overcome the 
problems exposed in practice will be asked for future studies, and the outcome of this paper can be used as reference for future studies.

Author Contributions: J.W. conceived the study and wrote the paper. N.K.T. provided valuable comments and suggestions on this paper. All the authors read and approved the final manuscript.

Funding: This research was funded by the MOE (Ministry of Education in China) Project of Humanities and Social Sciences (Grant No. 16YJC630141); the Soft Science Research Program of Shaanxi Province (Grant No. 2017KRM034); Xi'an Municipal Social Science Foundation (Grant No. 18J141); the Fundamental Research Funds for the Central Universities of China (Grant No. 310823170656).

Conflicts of Interest: The authors declare no conflict of interest.

\section{References}

1. Zhou, K.L.; Yang, S.L.; Shao, Z. Energy Internet: The business perspective. Appl. Energy 2016, 178, 212-222. [CrossRef]

2. Bedi, G.; Venayagamoorthy, G.K.; Singh, R.; Brooks, R.R.; Wang, K. Review of Internet of Things (IoT) in Electric Power and Energy Systems. Proc. IEEE IOT 2018, 5, 847-870. [CrossRef]

3. Zhu, J.; Xie, P.; Xuan, P.; Zou, J.; Yu, P. Renewable energy consumption technology under energy internet environment. In Proceedings of the 2017 IEEE Conference on Energy Internet and Energy System Integration (EI2), Beijing, China, 26-28 November 2017; pp. 1-5. [CrossRef]

4. Cheng, L.; Qi, N.; Zhang, F.; Kong, H.; Huang, X. Energy Internet: Concept and practice exploration. In Proceedings of the 2017 IEEE Conference on Energy Internet and Energy System Integration (EI2), Beijing, China, 26-28 November 2017; pp. 1-5. [CrossRef]

5. Park, L.W.; Lee, S.; Chang, H. A Sustainable Home Energy Prosumer-Chain Methodology with Energy Tags over the Blockchain. Sustainability 2018, 10, 658. [CrossRef]

6. The Promise of the Blockchain: The Trust Machine. Available online: http://mt.sohu.com/20161021/ n470943606.shtml (accessed on 18 January 2017).

7. Yan, Y.; Zhao, J.H.; Wen, F.S.; Chen, X.Y. Blockchain in Energy System: Concept, Application and Outlook. Electr. Power Constr. 2017, 38, 12-20.

8. Wang, K.; Hu, X.; Li, H.; Li, P.; Zeng, D.; Guo, S. A Survey on Energy Internet Communications for Sustainability. Proc. IEEE Trans. Sustain. Comput. 2017, 2, 231-254. [CrossRef]

9. Dou, C.; Yue, D.; Han, Q.; Guerrero, J.M. Multi-Agent System-Based Event-Triggered Hybrid Control Scheme for Energy Internet. IEEE Access. 2017, 5, 3263-3272. [CrossRef]

10. Giungato, P.; Rana, R.; Tarabella, A.; Tricase, C. Current Trends in Sustainability of Bitcoins and Related Blockchain Technology. Sustainability 2017, 9, 2214. [CrossRef]

11. Melanie, S. Blockchain: Blueprint for a New Economy, 1st ed.; O'Reilly: Farnham, UK, 2015.

12. Harald, V.K. Sustainability of bitcoin and blockchains. Curr. Opin. Environ. Sustain. 2017, 28, 1-9.

13. White Paper on China's Blockchain Technology and Application Development. 2016. Available online: http:/ / mt.sohu.com/20161021/n470943606.shtml (accessed on 21 October 2017).

14. Yuan, Y.; Wang, F.Y. Blockchain Technology Development Status and Prospects. Proc. Acta Autom. Sin. 2016, $42,481-494$.

15. Zhang, N.; Wang, Y.; Kang, C.Q.; Cheng, J.N.; He, D.W. Blockchain Technology in Energy Internet: A Study of Research Framework and Typical Applications. Proc. CSEE 2016, 36, 4011-4023.

16. SWS Research. Block Chaining Technology: Disruptive Innovation-Block Chain and Digital Currency Series Report (Two); SWS Research: Shanghai, China, 2016; pp. 1-35.

17. MOODY'S. Credit Strategy-Robust, Cost-Effective Applications Key to Unlocking Blockchain's Potential Credit Benefits. Available online: https://www.moodys.com/research/Moodys-Blockchain-can--bringbenefits-to-the-financial-industry-and-PR_352414 (accessed on 21 July 2016).

18. Yang, T.T.; Guo, Q.L.; Tai, X.; Sun, H.B.; Zhang, B.M.; Zhao, W.L.; Lin, C.H. Applying blockchain technology to decentralized operation in future energy internet. In Proceedings of the 2017 IEEE Conference on Energy Internet and Energy System Integration (EI2), Beijing, China, 26-28 November 2018; pp. 1-5.

19. Tan, L.; Chen, G. Blockchain 2.0; Electronic Industry Press: Beijing, China, 2016. 
20. Sun, H.; Mao, H.L.; Bai, X.M.; Chen, Z.D.; Hu, K.; Yu, W. Multi-Blockchain Model for Central Bank Digital Currency. In Proceedings of the 2017 18th International Conference on Parallel and Distributed Computing, Applications and Technologies (PDCAT), Taipei, Taiwan, 18-20 December 2017; pp. 360-367.

21. Zheng, Z.B.; Xie, S.A.; Dai, H.N.; Chen, X.P.; Wang, H.M. An Overview of Blockchain Technology: Architecture, Consensus, and Future Trends. In Proceedings of the 2017 IEEE International Congress on Big Data (Big Data Congress), Honolulu, HI, USA, 25-30 June 2017; pp. 557-564.

22. Bitcoin Traffic Bulletin. Available online: http://hashingit.com/analysis/34-bitcoin-traffic-bulletin (accessed on 11 November 2014).

23. Bitcoin Traffic Bulletin (Redux). 2015. Available online: http://hashingit.com/analysis/44-bitcoin-trafficbulletin-redux (accessed on 20 December 2015).

24. Yang, D.C.; Zhao, X.Y.; Xu, Z.X.; Li, Y.; Li, Q. Analysis and Prospect of the Application Status of Blockchain in Energy Internet. Proc. CSEE 2017, 37, 3664-3671.

25. Cai, W.D.; Yu, L.; Wang, R.; Deng, E.Y. Research on Development Method of Application System Based on Blockchain. J. Softw. 2017, 28, 1474-1487.

26. Ou, Y.X.; Zhu, X.Q.; Ye, L.; Yao, J.G. Preliminary Study on the Application of Blockchain Technology in Direct Purchase of Large Users. Proc. CSEE 2017, 37, 3737-3745.

27. Tencent Blockchain Solution White Paper. Available online: https://wenku.baidu.com/view/ 66dac81666ec102de2bd960590c69ec3d5bbdbfb.html (accessed on 23 October 2017).

28. Ding, W.; Wang, G.C.; Xu, A.D.; Chen, H.J.; Hong, C. Research on Key Technologies and Information Security Issues of Energy Blockchain. Proc. CSEE 2018, 38, 1026-1034, 1279.

29. Wu, G.; Zeng, B.; Li, R.; Zeng, B. Research on Application Mode of Blockchain Technology in Response to Resource Transaction in Integrated Demand Side. Proc. CSEE 2017, 37, 3717-3728.

30. O’Dwyer, K.J.; Malone, D. Bitcoin mining and its energy footprint. In Proceedings of the 25th IET Irish Signals \& Systems Conference 2014 and 2014 China-Ireland International Conference on Information and Communications Technologies (ISSC 2014/CIICT 2014), Limerick, Ireland, 26-27 June 2013; pp. 280-285.

31. Zeng, B.; Cheng, J.; Wang, Y.Q.; Li, Y.F.; Yang, Y.Q.; Dou, J.Y. Preliminary Study on the Multi-module Cooperative Autonomy Model of Energy Internet under the Blockchain Framework. Proc. CSEE 2017, 37, 3672-3681.

32. Gong, M. Simply Talk about What Exactly Is 'Blockchain' Technology. Available online: http://mt.sohu. com/20151023/n424005566.shtml (accessed on 23 October 2015).

33. Ethereum White Paper. A Next-Generation Smart Con-Tract and Decentralized Application Platform. 2015. Available online: https:/ / github.com/ethereum/wiki/wiki/White-Paper (accessed on 12 November 2015).

34. Peters, G.W.; Panayi, E. Understanding Modern Banking Ledgers through Blockchain Technologies: Future of Transaction Processing and Smart Contracts on the Internet of Money, 1st ed.; Springer International Publishing: Berlin, Germany, 2016; pp. 1-30.

35. Swan, M. Blockchain thinking: The brain as a decentralized autonomous corporation. IEEE. Technol. Soc. Mag. 2015, 34, 41-52. [CrossRef]

36. Blockchain Market by Provider, Application, Organization Size, Industry Vertical, and Region—Global Forecast to 2022. Available online: https:/ / www.marketsandmarkets.com/Market-Reports/blockchain-technology--market90100890.html (accessed on 1 December 2017).

37. Government Office for Science. Distributed Ledger Technology: Beyond Block Chain. Available online: https:/ / www.gov.uk/government/uploads/system/uploads/attachment_data/file/492972/gs-16-1distributed-ledger-technology.pdf (accessed on 24 February 2017).

38. State Council of the People's Republic of China. 'Thirteenth Five-Year' National Informatization Plan. Available online: http:/ / www.gov.cn/zhengce/content/2016-12/27/content_5153411.Htm (accessed on 24 February 2017).

39. Nasdaq Linq Claims to Have Issued First Securities over a Blockchain. Available online: https:/ / bravenewcoin.com/news/nasdaq-linq-claims-to-have-issued-first-securities-over-a-blockchain (accessed on 1 January 2016).

40. Blockchain the Subversive of the Rules of the Banking Industry. Available online: http:/ / chainb.baijia.baidu. com/article/472991 (accessed on 27 May 2017).

41. Cao, J. Analysis of the status quo of China's solar energy industry development and related legal issues. Sci. Technol. Innov. Intellect. Prop. 2012, 4, 3-22. 
42. Huang, A.Q.; Crow, M.L. The Future Renewable Electric Energy Delivery and Management (FREEDM) System: The Energy Internet. Proc. IEEE 2011, 99, 133-148. [CrossRef]

43. Rifkin, J. The Third Industrial Revolution; Palgrave Macmillan: London, UK, 2011.

44. Dong, C.Y.; Zhao, J.H.; Wen, F.S.; Xue, Y.S. From Smart Grid to Energy Internet: Basic Concepts and Research Framework. Proc. Autom. Electron. Power Syst. 2014, 38, 1-11.

45. Ma, Z.; Zhou, X.X.; Shang, Y.W.; Sheng, W.X. Exploration of the concept, key technology and development model of Energy Internet. Proc. Power Syst. Technol. 2015, 39, 3014-3022.

46. Ming, Z.; Jun, C. Research in multi-modularized cooperative self-managed Energy Internet in structure of blockchain. Proc. CSEE 2017, 37, 3672-3681.

47. Shiming, T.; Wenpeng, L. Structure and pivotal technology of Energy Internet. Proc. CSEE 2015, 35, 3482-3494.

48. What Is the Market Outlook When the Blockchain and Energy Are Combined? Available online: http: / / www.sohu.com/a/217332144_184860 (accessed on 17 January 2018).

49. Aitzhan, N.Z.; Svetinovic, D. Security and privacy in decentralized energy trading through multi-signatures, blockchain and anonymous messaging streams. IEEE Trans. Dependable Secur. Comput. 2016, 99, 1. [CrossRef]

50. Burger, C.; Kuhlmann, A. Blockchain in the Energy Transition: A Survey among Decision-Makers in the Germany Energy Industry; German Energy Agency Energy Systems and Energy Services: Berlin, Germany, 2016; pp. 5-40.

51. Mannaro, K.; Pinna, A.; Marchesi, M. Crypto-trading: Blockchain-oriented energy market. In Proceedings of the 2017 AEIT International Annual Conference, Cagliari, Italy, 20-22 September 2017; pp. 1-5. [CrossRef]

52. Sabounchi, M.; Wei, J. Towards resilient networked microgrids: Blockchain-enabled peer-to-peer electricity trading mechanism. In Proceedings of the 2017 IEEE Conference on Energy Internet and Energy System Integration (EI2), Beijing, China, 26-28 November 2017; pp. 1-5. [CrossRef]

53. Hou, Y.; Chen, Y.; Jiao, Y.; Zhao, J.; Ouyang, H.; Zhu, P.; Wang, D.; Liu, Y. A resolution of sharing private charging piles based on smart contract. In Proceedings of the 2017 13th International Conference on Natural Computation, Fuzzy Systems and Knowledge Discovery (ICNC-FSKD), Guilin, China, 29-31 July 2017; pp. 3004-3008. [CrossRef]

54. Shared Charging Piles for Electric Vehicles Based on Blockchain Theory in USA. Available online: http: / / www.sohu.com/a/157763955_681829 (accessed on 17 July 2017).

55. JuiceNet: Vehicle-to-Grid Integration Platform. Available online: https://emotorwerks.com/products/ juicenet-software/juicenet (accessed on 28 August 2018).

56. What Is the Warning Significance of Hacking Attacks on the Ukrainian Power Grid? Available online: http:/ / news.bjx.com.cn/html/20160126/704601.shtml (accessed on 26 January 2016).

57. Kyoto Protocol. Available online: https:/ / en.wikipedia.org/wiki/Kyoto_Protocol (accessed on 11 November 2001).

58. IBM Develops Blockchain Platform to Fight Carbon Emissions in China. Available online: https://www.ccn. com/ibm-develops-blockchain-platform-to-fight-carbon-emissions-in-china (accessed on 30 March 2017).

59. Xiaoping, Z.; Jianing, L. Energy distribution network: From virtual electric power plant to electric system. Proc. CSEE 2015, 14, 3532-3540.

60. Pazouki, S.; Haghifam, M. The impacts of virtual power plants on multiple carrier energy networks. In Proceedings of the 5th conference on thermal power plants (CTPP), Tehran, Iran, 10-11 June 2014.

61. Watanabe, H.; Fujimura, S.; Nakadaira, A. Blockchain Contract: Securing a Blockchain Applied to Smart Contracts. In Proceedings of the 2016 IEEE International Conference on Consumer Electronics (ICCE), Las Vegas, NV, USA, 7-11 January 2016; pp. 467-468.

62. Wei, S.; Yue, H. Operation and dispatch model for virtual power plant based on power blockchain network. Proc. CSEE 2017, 37, 3729-3736.

63. Yi, W.; Ning, Z. Optimized design and operation to energy pivots in Energy Internet review. Proc. CSEE 2015, 35, 5669-5681.

64. Mihaylov, M.; Jurado, S.; Avellana, N. NRGcoin: Virtual currency for trading of renewable energy in smart grids. In Proceedings of the 11th International Conference on the European Energy Market (EEM14), Krakow, Poland, 28-30 May 2014; pp. 1-6.

65. Hao, H.; Sanandaji, B.M.; Poolla, K. A generalized battery model of a collection of thermostatically controlled loads for providing ancillary service. In Proceedings of the 51st Annual Allerton Conference on Communication, Control, and Computing, Allerton House, UIUC, Monticello, IL, USA, 2-4 October 2013; pp. 551-558. 
66. Meyn, S.P.; Barooah, P.; Busic, A. Ancillary service to the grid using intelligent deferrable loads. IEEE Trans. Autom. Contr. 2015, 60, 2847-2862. [CrossRef]

67. Pavlak, G.S.; Henze, G.P.; Cushing, V.J. Optimizing commercial building participation in energy and ancillary service markets. Energy Build. 2014, 81, 115-126. [CrossRef]

68. Ma, O.; Alkadi, N.; Cappers, P. Demand response for ancillary services. IEEE Trans. Smart Grid 2013, 4, 1988-1995. [CrossRef]

69. Zhe, W.; Zhang, Z. Research on distribution network data fusion considering renewable energy. In Proceedings of the 2nd International Conference on Power and Renewable Energy (ICPRE), Chengdu, China, 20-23 September 2017.

70. Haring, T.W.; Mathieu, J.L. Comparing centralized and decentralized contract design enabling direct load control for reserves. IEEE Trans. Power Syst. 2016, 31, 2044-2054. [CrossRef]

71. Mohsenian-Rad, A.H.; Wong, V.W.; Jatskevich, J.; Schober, R.; Leon-Garcia, A. Autonomous demand-side management based on game-theoretic energy consumption scheduling for the future smart grid. IEEE Trans. Smart Grid 2010, 1, 320-331. [CrossRef]

72. Yang, X.D.; Zhang, Y.B.; Lu, J.J.; Zhao, B.; Huang, F.T.; Qi, J.; Pan, H.W. Blockchain-based automated demand response method for energy storage system in an energy local network. Proc. CSEE 2017, 37, 3703-3716.

73. Bin, L.; Chao, L. Research in implementation of automatic demand response system based on blockchain theory. Proc. CSEE 2017, 37, 3691-3702.

74. Blockchain Technology Drives the Arrival of the Power Revolution. Available online: http://www. bloomberg.com/news/articles/2016-09-12/bitcoin-technology-harnessed-to-push-electricity-revolution (accessed on 15 September 2016).

75. An Indie. Off-the-Grid, Blockchain-Traded Solar Power Market Comes to Brooklyn. Available online: http: / motherboard.vice.com/read/the-plan-to-power-brooklyn-with-a-blockchain-based-microgridtransactive-solar (accessed on 18 March 2016).

76. An Energy Blockchain for European Prosumers. Available online: https://bitcoinmag-azine.com/articles / an-energy-blockchain-for-european-prosumers-1462218142 (accessed on 2 May 2016).

77. Blockchain Electricity. Available online: http://www.fintechblue.com/2016/05/blockchain-electricity/ (accessed on 12 May 2016).

78. How Blockchain Technology Can Reinvent the Power Grid. Available online: http://fortune.com/2016/05/ 15/blockchain-reinvents-power-grid/ (accessed on 15 May 2016).

79. What Applications Are Blockchains in the Energy Sector? Available online: http://www.in-en.com/article/ html/energy-2262222.shtml (accessed on 14 July 2017).

80. Energy Plus Blockchain: Promising Future or Speculation. Available online: http://www.tmtpost.com/ 2435687.html (accessed on 14 May 2016).

81. Panda Green Energy Deploys Energy Blockchain to Realize Sustainable Energy Interconnection in the Future. Available online: http:/ / finance.sina.com.cn/roll/2018-02-08/doc-ifyrkrva4933612.shtml (accessed on 8 February 2018).

82. Bitcoin Energy Consumption Index. Available online: https://digiconomist.net/bitcoin-energyconsumption (accessed on 1 November 2017).

83. This City Just Passed the First Bitcoin Mining Ban in the US. Available online: https://motherboard.vice. com/en_us/article/8xk4qv / bitcoin-ban-plattsburgh-coinmint-mining (accessed on 16 March 2018).

84. 2018 Talent Trend Report. Available online: http://www.useit.com.cn/thread-18282-1-1.html (accessed on 13 March 2018).

(C) 2018 by the authors. Licensee MDPI, Basel, Switzerland. This article is an open access article distributed under the terms and conditions of the Creative Commons Attribution (CC BY) license (http://creativecommons.org/licenses/by/4.0/). 